\title{
MORTALITY OF COHORT OF VERY YOUNG INJECTING DRUG USERS IN PRAGUE, 1996-2010
}

\author{
Tomáš Zábranský1, 2, Ladislav Csémy ${ }^{1,3}$, Kateřina Grohmannová1,2 , Barbara Janíková1, 2 , Jiří Brenza ${ }^{1,2}$ \\ ${ }^{1}$ Centre for Addictology, Department of Psychiatry, First Faculty of Medicine, Charles University in Prague, Czech Republic \\ ${ }^{2}$ General University Hospital in Prague, Czech Republic \\ 3Prague Psychiatric Centre, Charles University in Prague, Czech Republic
}

\section{SUMMARY}

Aim: To determine the mortality in a cohort of very young injecting drug users (IDUs), and the factors associated with it.

Design: A database linkage prospective (follow-up) cohort study.

Setting: A convenience sample of clients of 2 low-threshold facilities, 1 drug treatment clinic, and one special facility for children with severe behavioural disorders, who were all younger than 19 and older than 15, was interviewed one or more times in 1996-8 and asked to agree with their being interviewed again after 10 or more years.

Participants: 151 (65 male, 86 female) IDUs recruited in October 1996 - December 1998.

Measurement: Database linkage study compared unique identifiers (IDs) of the recruited subjects with the general register of deaths to determine the life status, and the causes of death of those deceased. Where necessary, we examined the death protocols directly.

Findings: Altogether, 8 deaths were registered between recruitment and 31st December 2008 (1,660 person-years). All the deceased were male, and all their deaths were "unnatural" - that is, caused by drug overdose or accident. This translates into the crude mortality rates for the whole cohort being 4.8 deaths per 1,000 person-years (PY), and into a specific mortality ratio in the males SMR=14.4 with the peak at the age of 15-20 (SMR=60.1), declining to $S M R=8.2$ at the age of 25-30. Except gender, we found no "predictors of death" in this high-risk cohort.

Conclusion: The overall mortality in the cohort was substantially higher than in the general population; in the male part of the cohort of young injecting drug users it was excessively high in the first three years after recruitment, and caused by external causes exclusively; the mortality in the female sub-cohort was zero, i.e. lower than in the general population of the same age range. Our findings suggest a need to develop targeted prevention of overdoses and other unnatural deaths in young male drug injectors.

Key words: survival analysis; injecting drug use; methamphetamine; heroin; drug abuse; Czech Republic

Address for correspondence: T. Zábranský, Centre for Addictology, Department of Psychiatry, First Faculty of Medicine, and General University Hospital, Charles University in Prague, Ke Karlovu 11, 12000 Praha 2, Czech Republic. E-mail: twz@adiktologie.cz

\section{INTRODUCTION}

The mortality of some illegal drugs users, and IDUs in particular, is known to be extremely high when compared with the general population - albeit differing from one group of drug users to another depending on factors such as sociodemography, the availability of specialised services, and others - in most of the "Western world".

A major review that summarised the results of studies on the overall mortality of drug users performed in the European Union Member States in the period from the 1960s through to 2007 found a low level of mutual comparability both in terms of the methodologies used and the definitions of the target population (1); however, most of the overall mortality studies studied heroin injectors and almost all of them recruited exclusively "problem drug users" as defined by the European Monitoring Centre for Drug Addiction (EMCDDA), that is, long-term and regular and/ or injecting users of opioids and/or cocaine and/or amphetaminetype drugs (2). The "approximate, modal or typical results" were: crude mortality rate $1-2 \%$ annually, with injectors' modus at $3 \%$; overdoses accounted for $20-60 \%$ of the overall mortality of drug users in the studies reviewed, and the proportion of $40 \%$ seemed to be an "average" figure for fatal overdoses as causes of death in the studies reviewed. Major differences in overall mortality were found between "high-HIV" and "low-HIV" EU countries; in Italy, Spain, Scotland and in some German studies, HIV-related deaths accounted for as much as approximately $40 \%$ of the mortality of drug users. The majority of the studies reviewed (1) reported standardised mortality ratios (SMR) to be between 10 and 15 .

According to a recent review paper with a wider geographic scope than the previous one, the crude mortality rate (CMR) of opiate users is estimated to be 2.09 deaths per 100 person-years (PY) $(95 \%$ CI; $1.93,2.26)$ globally, and the standardised mortality ratio (SMR) is estimated to be as high as 14.26 (95\% CI: 12.82 , 16.50 ), with males having a higher CMR and lower SMR than females (3). For users of stimulants, fewer studies of sufficient quality are available; the recent review reports the CMRs as ranging from 0 in Australia to 2.95 in Thailand; the SMRs were not found for stimulant users except a 2007 Czech study (4-6). A new Swedish study of 561 patients admitted to detoxification in 1970-78 found the SMR to be 5.94, with a large SMR difference in subjects aged 20-44 $(\mathrm{SMR}=18)$ and $45+(\mathrm{SMR}=5)$. As 
for predictors of death, in an Australian study of the mortality of users of opiates, the only statistically significant predictor was a prior history of opiate overdoses (7); in other studies, there are no statistically significant predictors found, and some of the suspected predictors can be rather seen as "proxies" of "chaotic lives" - typically, history of a frequent imprisonment, or the reported use of "drug cocktails" in one injection (for the concept of the "chaotic live proxies", see, e.g., 8).

\section{MATERIAL AND METHODS}

In 1995-1998, Csemy ran a set of surveys and field studies in different groups of adolescents and young adults using and not using drugs; the studies were parts of a broader project seeking predictors of several types of risky behaviours (9). One of the groups studied consisted of 183 injecting drug users younger than nineteen and older than fifteen years of age. All the members of this group were interviewed thoroughly, answering questions on their social and demographic status, their drug career, and a set of other questions. Field researchers asked every study participant to agree with their further participation in a follow-up study that would include further interviews "after 10 or more years after recruitment" within the process of informing them about the study and their signing an informed consent. Of the 183 participants approached, 151 agreed and were included in the reported follow-up study. The main characteristics of our sample are shown in Table 1.

In 2010, we conducted a database linkage study in order to examine the life status of the 151 participants who agreed to be followed up. The IDs used for linkage of the database of participants in the 1990s study with the general mortality register was their personal ID enciphered by the control sum-based one-way ciphering program "EpiCrypt", which is approved for use in similar studies by the Czech Office for Personal Data Protection as unbreakable by any other means than a brute force attack, which is seen by this national data protection authority as technically unreasonable (10). We used the STATA 11 statistical package for data management and analysis.

\section{RESULTS}

We followed our cohort for 1,659.7 person-years (M 676.3 PY, F 983.4 PY), of which the heroin users were followed for 692.0 PY, users of pervitin (methamphetamine) for 863.2 PY, and users of other drugs for 104.6 PY. After linking the databases, we identified 8 cases of death in our cohort in the period between their recruitment and 31st December 2008. After a careful verification of the death causes and in cases where the ICD-10 coding (11) in the general mortality database was absent or ambivalent, we identified the deaths, their causes and principal characteristics of the deceased as summarised in Table 2.

All of the cases of death were found in males; in females, no death was registered during the follow-up period; this represents a level of mortality "lower" than expected in the standardised female population. All the cases of death were "unnatural" - that is, caused by external causes. Four deaths (numbers $2-5$ in Table 2; $50 \%$ of all those identified) were caused by a lethal overdose of an illegal drug; another fatal overdose (No. 1 in Table 2) was a suicide committed with cyanide and yet another lethal overdose (No. 8 in Table 2) was caused by (legal) alcohol. The remaining two deaths were (violent) accidents, with one of the two cases (No. 6 in Table 2) representing another suspected suicide (hit by a train).

Our findings represent high crude mortality rates of $1.48 \%$ per year for males, and $0.48 \%$ per year for the whole cohort. Given the extremely young age of the cohort members, this translates into a very high specific mortality ratio for males $(S M R=14.4)$ with the peak at the age of $15-20(\mathrm{SMR}=60.1)$, declining to $\mathrm{SMR}=8.2$ at the age of 25-30. The highest SMR was found in the male heroin injectors aged 15-19 (point estimate 127.8); the peak of mortality for methamphetamine (pervitin) occurred somewhat later, in the 20-24 age group (for details, see Table 3; for survival estimate of males in the cohort and the cumulative hazard estimates for both genders see Figures 1 and 2, respectively).

We attempted to find "predictors" of death, using as independent variables the sociodemographic data, variables related to drug career, data covering mental health and family anamnesis, and

Table 1. The sample characteristics

\begin{tabular}{|c|c|c|c|}
\hline Variable & Male & Female & Total \\
\hline $\mathrm{N}$ & 65 & 86 & 151 \\
\hline Average age at the time of recruitment & 18.2 years of age & 17.2 years of age & 17.6 years of age \\
\hline Median age at the time of recruitment & 18 years of age & 17 years of age & 18 years of age \\
\hline Opiate (heroin) as principal drug & $27(42 \%)$ & $38(44 \%)$ & $65(43 \%)$ \\
\hline Stimulant (methamphetamine = pervitin) as principal drug & $34(52 \%)$ & $43(50 \%)$ & $77(51 \%)$ \\
\hline Principal drug other than the two above & $4(6 \%)$ & $5(6 \%)$ & $9(6 \%)$ \\
\hline Recruitment in low-threshold drop-in centre 1 & $13(20 \%)$ & $14(16 \%)$ & $27(18 \%)$ \\
\hline Recruitment in low-threshold drop-in centre 2 & $45(69 \%)$ & $44(51 \%)$ & $89(59 \%)$ \\
\hline Recruitment in psychiatric hospital & $4(6 \%)$ & $15(17 \%)$ & $19(13 \%)$ \\
\hline Recruitment in detention facility for minors & $3(5 \%)$ & $6(7 \%)$ & $9(6 \%)$ \\
\hline Recruitment in children's home & $0(0 \%)$ & $7(8 \%)$ & $7(5 \%)$ \\
\hline
\end{tabular}

SMR estimates the excess of mortality rate of the cohort that was followed as compared with a standardised population, i.e. with the mortality of the "average" population of the same country with a gender and age structure identical to the cohort that was followed. 


\begin{tabular}{|c|c|c|c|c|c|c|c|c|}
\hline 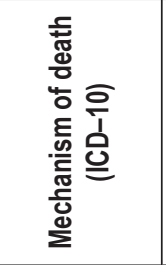 & 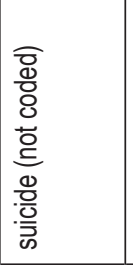 & 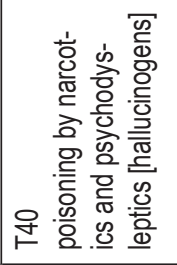 & 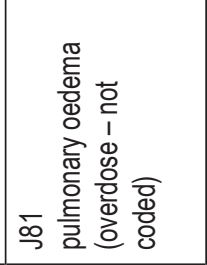 & 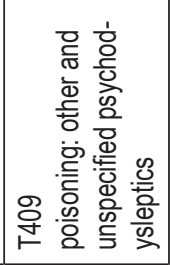 & 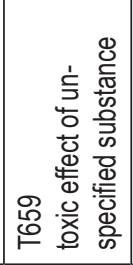 & 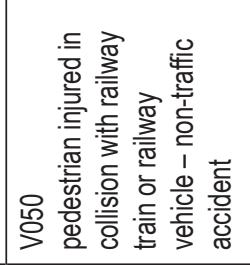 & 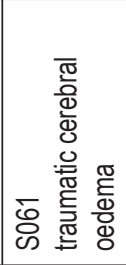 & $\frac{\pi}{z}$ \\
\hline 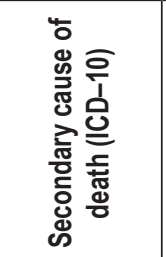 & 妾 & 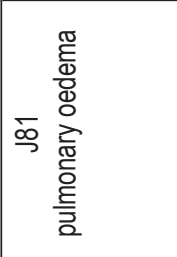 & 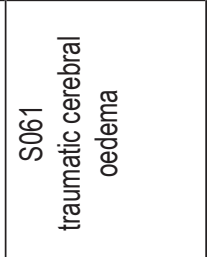 & 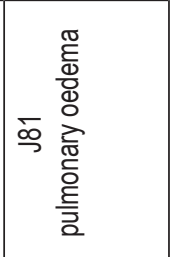 & 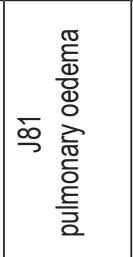 & 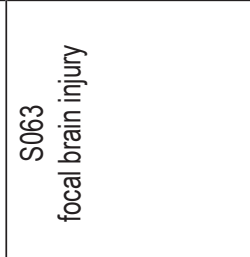 & 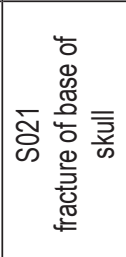 & 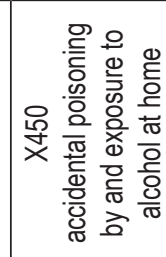 \\
\hline 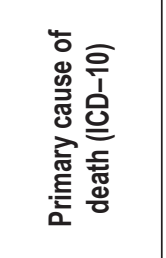 & 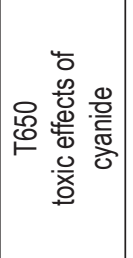 & 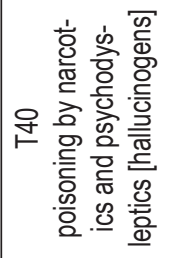 & 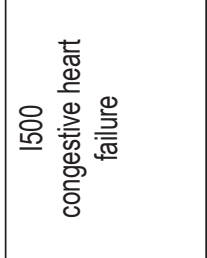 & 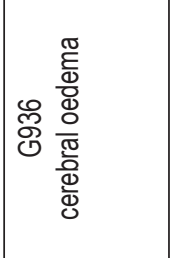 & 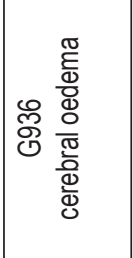 & 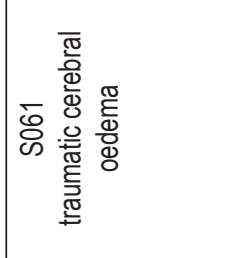 & 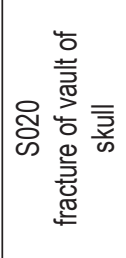 & 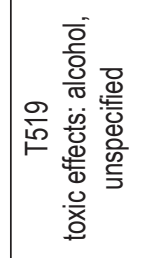 \\
\hline 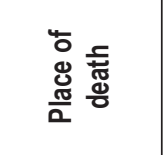 & 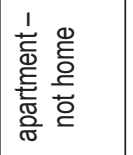 & \begin{tabular}{|l}
$\vec{\Phi}$ \\
$\frac{\mathbb{d}}{\omega}$
\end{tabular} & $\begin{array}{l}\overrightarrow{\mathbb{\Phi}} \\
\frac{\mathbb{w}}{\omega}\end{array}$ & 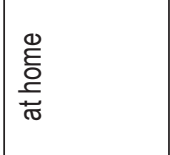 & $\begin{array}{l}\overrightarrow{\mathbb{\Phi}} \\
\frac{\underline{\omega}}{\omega}\end{array}$ & 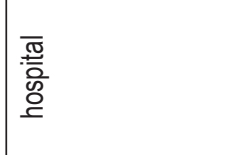 & $\begin{array}{l}\overrightarrow{\mathbb{\Phi}} \\
\frac{\mathbb{E}}{\omega}\end{array}$ & 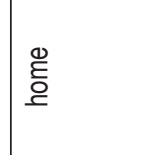 \\
\hline 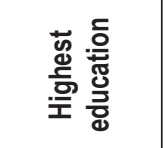 & 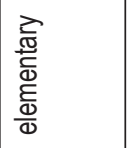 & 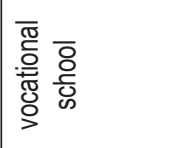 & 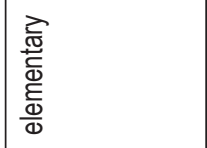 & 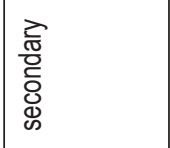 & 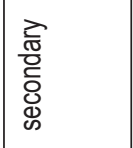 & 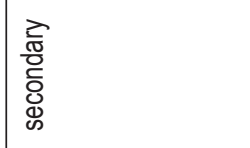 & 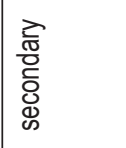 & 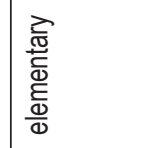 \\
\hline 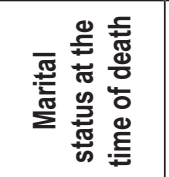 & $\begin{array}{l}\frac{\omega}{0} \\
\frac{5}{\infty}\end{array}$ & $\mid \frac{\frac{\omega}{O}}{\frac{D}{\omega}}$ & $\begin{array}{l}\frac{0}{0} \\
\frac{D}{\omega}\end{array}$ & \begin{tabular}{|l}
$\frac{0}{0}$ \\
$\frac{D}{\omega}$
\end{tabular} & $\begin{array}{l}\frac{0}{0} \\
\frac{D}{\omega}\end{array}$ & \begin{tabular}{|l}
$\frac{0}{0}$ \\
$\frac{D}{\omega}$
\end{tabular} & \begin{tabular}{|l}
$\frac{0}{0}$ \\
$\frac{D}{\omega}$
\end{tabular} & $\begin{array}{l}\frac{0}{0} \\
\frac{D}{\infty}\end{array}$ \\
\hline 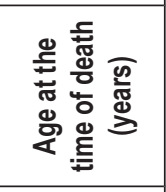 & $\stackrel{\stackrel{\rho}{r}}{\stackrel{2}{r}}$ & $\begin{array}{l}\infty \\
\infty \\
\infty\end{array}$ & $\hat{\dot{N}}$ & চ্் & $\stackrel{\tilde{g}}{\sigma}$ & $\stackrel{m}{\sim}$ & 㞧 & 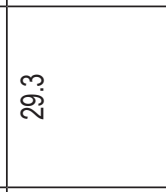 \\
\hline 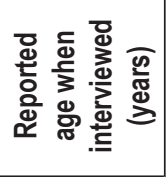 & $\neq$ & $\neq$ & $\stackrel{\circ}{\circ}$ & $\propto$ & 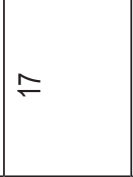 & $\propto$ & $\neq$ & 으 \\
\hline 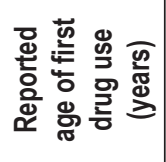 & $\approx$ & 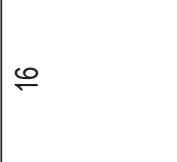 & $\dddot{m}$ & 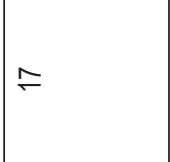 & $\neq$ & 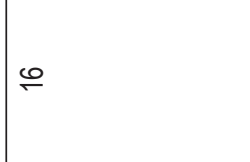 & $\neq$ & $\stackrel{2}{\circ}$ \\
\hline 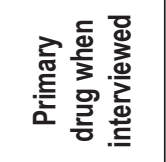 & 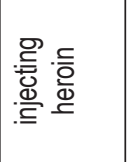 & 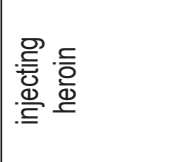 & 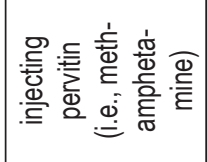 & 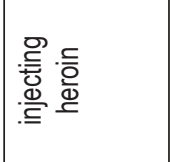 & 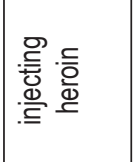 & 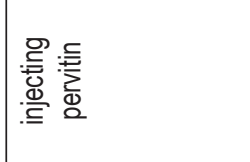 & 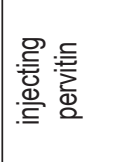 & 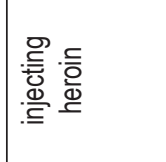 \\
\hline 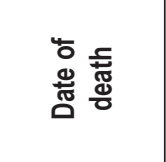 & $\begin{array}{l}\hat{o} \\
\text { o } \\
i \\
i \\
i\end{array}$ & $\begin{array}{c}\mathscr{8} \\
\stackrel{8}{\circ} \\
i \\
\infty \\
\infty \\
\infty\end{array}$ & 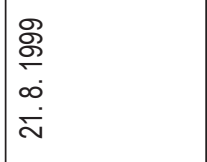 & 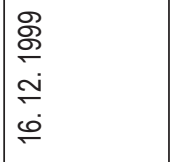 & $\begin{array}{l}8 \\
0 \\
0 \\
\dot{0} \\
\dot{p}\end{array}$ & 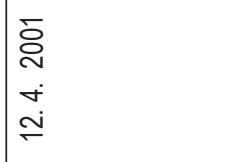 & $\begin{array}{l}\stackrel{2}{0} \\
\stackrel{d}{1} \\
\dot{-} \\
\dot{\sim}\end{array}$ & 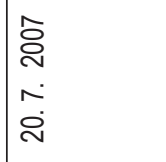 \\
\hline 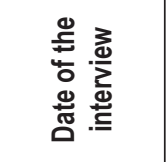 & 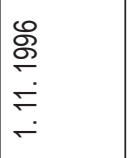 & 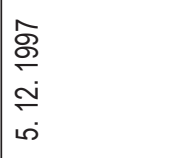 & $\begin{array}{l}\hat{\sigma} \\
\stackrel{9}{\circ} \\
0 \\
\infty \\
\infty\end{array}$ & $\begin{array}{l}\infty \\
\stackrel{\infty}{O} \\
\stackrel{0}{+} \\
0\end{array}$ & 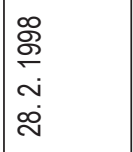 & 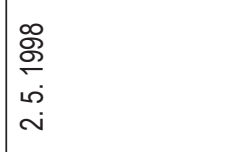 & $\begin{array}{l}\mathscr{8} \\
\stackrel{\circ}{\circ} \\
\stackrel{0}{0} \\
\stackrel{-}{-}\end{array}$ & $\begin{array}{l}\hat{8} \\
\stackrel{8}{0} \\
0 \\
\dot{m}\end{array}$ \\
\hline & - & $\sim$ & $m$ & ナ & مـ & 0 & $n$ & $\infty$ \\
\hline
\end{tabular}




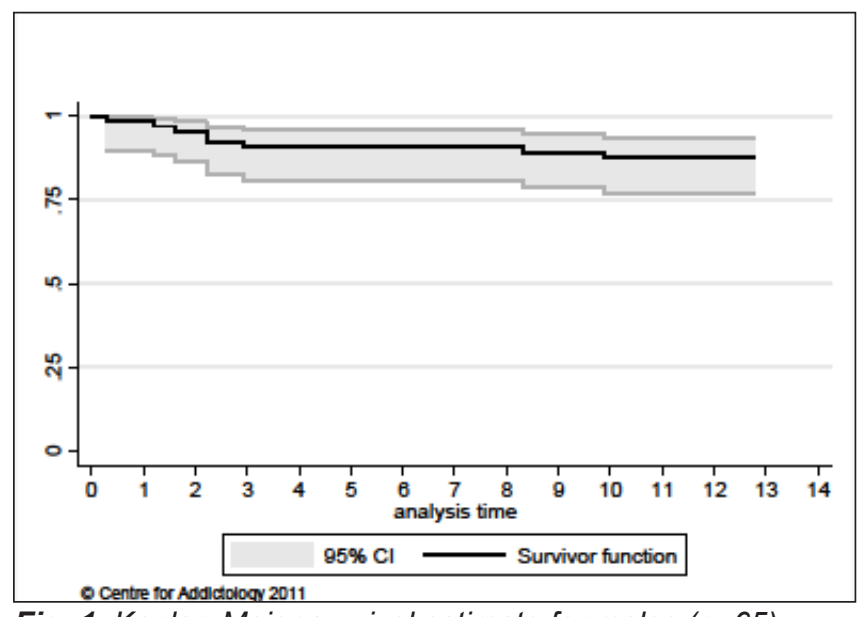

Fig. 1. Kaplan-Meier survival estimate for males ( $n=65)$.

variables related to contacts with helping institutions, all of which were gathered by Csemy's study in the 1990s (9). Altogether, we performed a set of statistical tests using 52 independent variables; however, in this phase of the study, we found no statistically significant predictors of death in our cohort except gender $(p<0.001)$. Similarly, we did not find any statistically significant proportional hazard model.

\section{DISCUSSION}

The recruitment took part in the declining phase of the first (and, so far, last) heroin epidemic, which hit the Czech Republic in the early 1990s and was particularly pronounced and visible in the capital city, Prague, and in Western Bohemia (for details, see, e.g., 12-15). Early after the fall of communism, problem

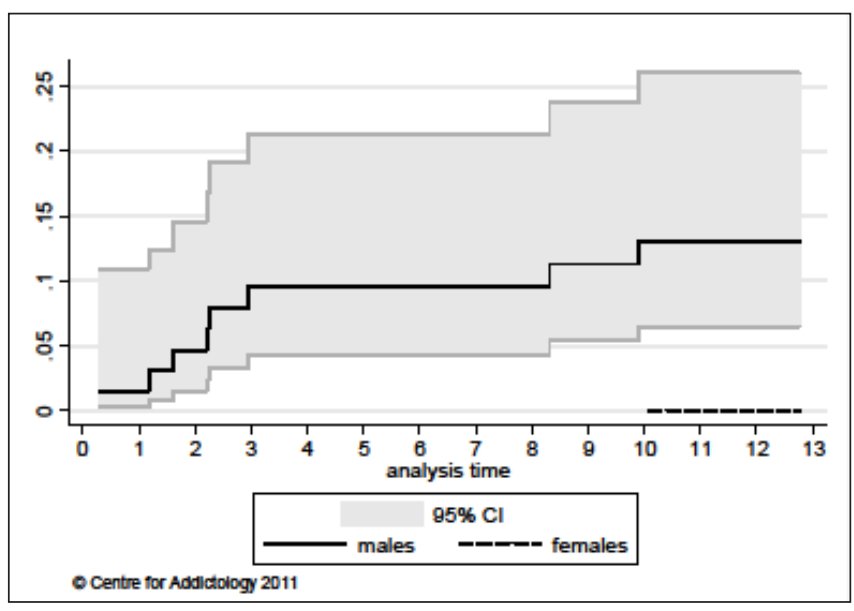

Fig. 2. Nelson-Aalen cumulative hazard estimates.

drug use was less concentrated in the marginalised and socially disadvantaged strata of society than in countries with a longer drug history, and the Czech Republic nowadays: of the 151 members of our cohort, only eleven people were homeless/living on the street, and 100 of the study participants lived with their parents at the time of recruitment, when they were using the service(s) specified in Table 1. Despite the relatively low number of members in our cohort, which represents its main limitation, the relatively long follow-up period makes our study unique since to the best of our knowledge it is the only prospective cohort study covering quite different periods of the Czech "drug history".

Most of the deaths occurred at a very young age and relatively shortly after recruitment; as it is obvious in the cumulative hazard function, after a "high-risk" period that is as long as 3 years after recruitment, a long plateau followed, with two deaths at the end of the follow-up period (see Fig. 2). Except one suicidal poisoning,

Table 3. Specific mortality ratios (SMRs) in males

\begin{tabular}{|c|c|c|c|c|c|}
\hline Age cohort & Person-years & Observed failures & Expected failures & SMR & $95 \%$ Conf. interval \\
\hline \multicolumn{6}{|l|}{ Methamphetamine } \\
\hline$(15-19)$ & 39.06 & 0 & 0.023435 & 0 & \\
\hline$(20-24)$ & 162.65 & 2 & 0.130122 & 15.37 & $3.84-61.46$ \\
\hline$(25-29)$ & 148.00 & 1 & 0.133191 & 7.51 & $1.06-53.30$ \\
\hline $30+$ & 15.92 & 0 & 0.015924 & 0 & \\
\hline \multicolumn{6}{|l|}{ Heroin } \\
\hline$(15-19)$ & 39.13 & 3 & 0.023479 & 127.77 & $41.21-396.17$ \\
\hline$(20-24)$ & 115.12 & 1 & 0.092099 & 10.86 & $1.53-77.08$ \\
\hline$(25-29)$ & 104.14 & 1 & 0.093726 & 10.67 & $1.50-75.74$ \\
\hline $30+$ & 5.59 & 0 & 0.005593 & 0 & \\
\hline \multicolumn{6}{|l|}{ Other } \\
\hline$(15-19)$ & 5.00 & 0 & 0.002998 & 0 & \\
\hline$(20-24)$ & 20.00 & 0 & 0.016 & 0 & \\
\hline$(25-29)$ & 19.00 & 0 & 0.017103 & 0 & \\
\hline $30+$ & 2.67 & 0 & 0.002667 & 0 & \\
\hline Males total & 676.28 & 8 & 0.556338 & 14.38 & $7.19-28.75$ \\
\hline
\end{tabular}


Table 4. Survival probabilities in the retrospective cohort study with 27,941 patients hospitalised as a result of drug-related disorders (except alcohol and tobacco) and/or being patients of the OST in the Czech Republic 1997-2007 (26) and in followup of the cohort of 151 young injectors in 1996-2008 (this study)

\begin{tabular}{|l|c|c|c|c|c|}
\hline Study & $\begin{array}{c}1 \text { year } \\
\text { after recruitment }\end{array}$ & 2 years & 3 years & 5 years & 10 years \\
\hline $\begin{array}{l}\text { The retrospective study with in-patients of } \\
\text { medical facilities 1997-2007 (N=27,491) }\end{array}$ & 0.9919 & 0.9856 & 0.9811 & 0.9721 & 0.9576 \\
\hline $\begin{array}{l}\text { The follow-up study of very young injectors } \\
(\mathrm{N}=151)\end{array}$ & 0.9934 & 0.9538 & 0.9077 & 0.9077 & 0.8769 \\
\hline
\end{tabular}

all these early deaths were caused by drug overdoses - despite the fact that our cohort includes larger number of methamphetamine injectors, three fatal overdoses were caused by heroin, and only one by methamphetamine, which is probably related to the different levels of toxicity of the two substances (16). Our findings are also in accord with the results of other studies of mortality among drug users, which show higher potential for overdoses in opiates than in stimulants, and point out the extremely elevated risk of fatal overdoses (and deaths in general) in young male injectors in the first years of their injecting careers $(3,4,17-19)$.

The comparison of our results with much larger cohorts from Czech retrospective studies of the mortality of medical in-patients and/or patients of opiate substitution treatment $(\mathrm{OST})(5,20)$ shows that the survival probabilities in our study are substantially lower (Fig. 1) than those found in the two extensive retrospective studies; in Table 4, we show the survival probabilities found in the larger and more recent retrospective study (20), where the cohort was recruited from patients of in-patient facilities and OST patients in 1997-2007. This difference in survival probabilities may be explained by the very young age in our cohort, and by the fact that most of the cohort participants were recruited in low-threshold facilities - that is, in facilities providing services to those users of illegal drugs who are not able and/or willing to cease their drug use (usually high-risk injecting drug use) at that moment; by definition, this is the second most vulnerable population of drug users (next to non-institutionalised problem drug users (see, e.g., 21, 22)).

In our study, all the deaths were violent and as such, preventable. Since naïve, young and relatively inexperienced drug users are those most at risk not only in terms of deaths, but also in terms of other health hazards such as blood-borne infections related to drug use $(23,24)$. Thus, our findings further stress the public health's need to develop interventions targeting this group of new injectors in order to protect their lives and health in general, such as active support for switching from injecting to other patterns of drug use with similar perceived drug effects (25), or the safe injecting rooms/facilities that are increasingly being introduced in the cities of the EU, Australia and the Americas (26).

\section{CONCLUSION}

The mortality in the male part of the cohort of young injecting drug users recruited in 1996-1998 in Prague was excessively high in the first three years after recruitment and all cases of death were caused by external causes exclusively. The mortality in females was zero, i.e. lower than in the general population of the same age group, and substantially lower than in other studies that included female drug users both abroad and in the Czech Republic.

Our findings suggest a need to develop targeted prevention strategy aimed at danger of overdoses and other unnatural causes of death in very young male drug injectors, and in new, "naïve" IDUs. Introduction and support for innovative harm reduction measures specific to these overlapping target groups should be considered in the Czech Republic.

\section{Acknowledgements}

We would like to thank for the support provided by the Institute of Health Information and Statistics of the Czech Republic and the highly useful advice and comments received from the head of its Department for Analyses, Publications and External Collaboration, Ms. Blanka Nechanská.

Statement on the conflict of interests, sponsorship and adherence to the ethical recommendations

This study was supported by the grant NS/10032-3/2008 of the Internal Grant Agency of the Ministry of Health of the Czech Republic.

Conflict of interests: none.

The study protocol was approved by the Ethical Committee of the General University Hospital, Charles University in Prague, by its decision as of 18th October 2007, and the study team has carefully adhered to the approved protocol and general ethical recommendations and rules including personal data protection.

\section{List of previous grant projects}

This study builds on the results of the grant NR1264 - IGA MZd of the Internal Grant Agency of the Ministry of Health of the Czech Republic.

\section{REFERENCES}

1. Mravčík V, Zábranský T, Chomynová P. Summary of EU countries situations in implementation of (overall) mortality studies. Review. Prague: ResAd2009; 2009. Report No.: 1. Contract No.: CT.07.EPI.060.1.2.

2. European Monitoring Centre for Drugs and Drug Addiction (EMCDDA). Key epidemiological indicator: prevalence of problem drug use. 1st ed. Lisbon: European Monitoring Centre for Drugs and Drug Addiction; 2004.

3. Degenhardt L, Bucello C, Mathers B, Briegleb C, Ali H, Hickman M, et al. Mortality among regular or dependent users of heroin and other opioids: a systematic review and meta-analysis of cohort studies. Addiction. 2011 Jan;106(1):32-51

4. Singleton J, Degenhardt L, Hall W, Zabransky T. Mortality among amphetamine users: a systematic review of cohort studies. Drug Alcohol Depend. 2009 Nov 1;105(1-2):1-8.

5. Lejckova P, Mravcik V. Mortality of hospitalized drug users in the Czech Republic. Journal of Drug Issues. 2007;37(1):103-18.

6. Lejcková P, Mravcík V. Mortality of drug users. Summary of cohort study results. Epidemiol Mikrobiol Imunol. 2005 Nov;54(4):154-60. (In Czech.)

7. Darke S, Mills KL, Ross J, Teesson M. Rates and correlates of mortality amongst heroin users: findings from the Australian Treatment Outcome 
Study (ATOS), 2001-2009. Drug Alcohol Depend. 2011 Jun 1;115(3):1905.

8. Zabransky T, Mravcik V, Korcisova B, Rehak V. Hepatitis C virus infection among injecting drug users in the Czech Republic - prevalence and associated factors. Eur Addict Res. 2006;12(3):151-60.

9. Csémy L. Youth and addictive substances. Final report of the grant project NR1264 - IGA MZd ČR. Prague: Ministry of Health of the Czech Republic; 1999. (In Czech.)

10. Office for Personal Data Protection. EpiCrypt Programme - the technical documentation. Prague: Office for Personal Data Protection; 2002. (In Czech.)

11. World Health Organization. International statistical classification of diseases and related health problems, tenth revision. Prague: Institut for Health Information and Statistics of the Czech Republic; 1992. (In Czech.)

12. Zábranský T. Czech drug laws as arena of drug policy battle. J Drug Issues. 2004;34(3):661-86.

13. Nožina M. Czech Drug Scene in 90s. In: Nožina M, editor. The Czech Drug World. Prague \& Orlík nad Vltavou: KLP - Koniasch Latin Press \& Livingstone; 1997. p. 223-302. (In Czech.)

14. Mravcík V, Nechanská B, St’astná L. Residential care for substance users and addicts in the Czech Republic according to the health statistics since 1959. Epidemiol Mikrobiol Imunol. 2011 Feb;60(1):21-31. (In Czech.)

15. Miovský M. Changing Patterns of Drug Use in the Czech Republic during the Post-Communist Era: A Qualitative Study. J Drug Issues. 2007;37(1):73-102

16. King LA, Corkery JM. An index of fatal toxicity for drugs of misuse. Hum Psychopharmacol. 2010 Mar;25(2):162-6.

17. Hedrich D, Vicente J, Fay P, editors. Overdose - a major cause of avoidable death among young people. 1st ed. Luxembourgh: Office for Official Publications of the European Communities; 2004.

18. Vicente J, Giraudon I, Matias J, Hedrich D, Wiessing L. Rebound of overdose mortality in the European Union 2003-2005: findings from the 2008 EMCDDA Annual Report. Euro Surveill. 2009 Jan 15;14(2). pii: 19088. Erratum in: Euro Surveill. 2009 Jan;14(3).
19. Vlahov D, Wang CL, Galai N, Bareta J, Mehta SH, Strathdee SA, et al. Mortality risk among new onset injection drug users. Addiction. 2004 Aug;99(8):946-54.

20. Zábranský T, Mravčík V, Chomynová P. Overal mortality of drug users in the Czech Republic. 1st ed. EMCDDA, editor. Prague / Lisbon: ResAd / EMCDDA; 2009.

21. Wall R, Rehm J, Fischer B, Brands B, Gliksman L, Stewart J, et al. Social costs of untreated opioid dependence. J Urban Health. 2000 Dec;77(4):688-722.

22. French MT, Salomé HJ, Carney M. Using the DATCAP and ASI to estimate the costs and benefits of residential addiction treatment in the State of Washington. Soc Sci Med. 2002 Dec;55(12):2267-82.

23. Bruneau J, Daniel M, Abrahamowicz M, Zang G, Lamothe F, Vincelette $\mathrm{J}$. Trends in human immunodeficiency virus incidence and risk behavior among injection drug users in Montreal, Canada: a 16-year longitudinal study. Am J Epidemiol. 2011 May 1;173(9):1049-58.

24. Mehta SH, Astemborski J, Kirk GD, Strathdee SA, Nelson KE, Vlahov $\mathrm{D}$, et al. Changes in blood-borne infection risk among injection drug users. J Infect Dis. 2011 Mar 1;203(5):587-94.

25. Mravčík V, Skařupová K, Orlíková B, Zábranský T, Karachaliou K, Schulte B. Use of gelatine capsules for application of methamphetamine: a new harm reduction approach. Int J Drug Policy. 2011 Mar;22(2):172-3.

26. Hedrich D, Kerr T, Dubois-Arber F. Drug consumption facilities in Europe and beyond. In: Rhodes T, Hedrich D, editors. Harm reduction: evidence, impacts and challenges. 1st ed. Luxembourg: Publications Office of the European Union; 2010. p. 305-31.

27. Zábranský T. Drug-related mortality. In: Mravčík V, editor. The Czech Republic - drug situation 2009. Prague: Office of the Czech Government; 2010. p. 113-9.

Received March 22, 2011 Accepted in revised form May 30, 2011 